\title{
ANALYTICAL STUDY OF STRESS DISTRIBUTION MODELS FOR ESTIMATION OF STRESSES BENEATH PLAIN RIGID WHEELS AND A VERTICAL FORCE ON TRI-1 LUNAR SOIL SIMULANT
}

\author{
Pala Gireesh Kumar \\ Department of Civil Engineering, Sri Vishnu Engineering College for Women, Bhimavaram, India \\ e-mail: palagireeshk@gmail.com; gireeshnitt04@gmail.com

\section{S. JAYALEKSHMI} \\ Department of Civil Engineering, National Institute of Technology Trichy, Tiruchirappalli, India \\ e-mail: jaya@nitt.edu; jaynagu@gmail.com
}

In this paper, three stress distribution models are considered, namely: Reece from 1965, Bekker from 1969, Wong-Reece from 1967. Two types of wheels are considered for the preset study, i.e., a small wheel with diameter of $160 \mathrm{~mm}$ and width $32 \mathrm{~mm}$, whereas for a large wheel with diameter of $210 \mathrm{~mm}$ and width of $50 \mathrm{~mm}$. TRI-1 or Tiruchirappalli soil simulant is considered for the interaction studies, which is an anorthosite based lunar soil simulant. The normal stress, shear stress and vertical forces are determined when the wheel starts moving on TRI-1 soil simulant. Entry and exit angles are also calculated for all models to estimate vertical forces. The maximum normal stress found for the small wheel was $32.121 \mathrm{kN} / \mathrm{m}^{2}$ (Wong-Reece model). In the case of the large wheel, the maximum normal stress was found to be $39.016 \mathrm{kN} / \mathrm{m}^{2}$ (Reece model). Vertical forces are found from the obtained normal stresses and shear stresses, and are presented graphically. The dimensionless stress ratio of both the wheels for the considered models, i.e., DNSR and DSSR, is also found.

Keywords: TRI-1 lunar soil simulant, stress distributions, entry and exit angels, vertical force, DNSR and DSSR

\section{Introduction}

Mobile robots are required for space exploration missions to navigate on rough terrain. Wheeled rovers and tracked rovers play a significant role in planetary space exploration missions. More than tracked rovers, wheeled rovers are mostly used in such exploration missions (Lizuka et al., 2010). These planetary exploration rovers have to achieve a stable travelling on uneven/rough terrain (Yoshikawa et al., 2017). Terrain is covered with lots of dust, obstacles and steep slopes, etc. A wheeled rover can get stuck in the loose soil and sometimes a mission fails (Sutoh et al., 2010). When the rover moves on such a planetary surface, it is important to understand the interaction between the rover wheel and the soil. In order to avoid such problems, it is necessary to investigate the interaction between the rover wheel and the soil, and its motion behaviour on a loose soil and on rough terrain (Yoshikawa et al., 2017). Understanding the stress distributions beneath the rigid wheels during its travel is important in investigating a wheeled rover moving on rough terrain. In this paper, three stress distribution models are considered to evaluate stresses that develop beneath the rigid wheels during motion travel on TRI-1 lunar soil simulant. TRI-1 or Tiruchirappalli-1 is an anorthosite based lunar soil simulant, developed and characterized by matching properties with Apollo-16 lunar soil (Sreenivasulu, 2014). Two wheels of known geometry are considered for the present study, i.e., a small wheel (diameter $160 \mathrm{~mm}$ and width $32 \mathrm{~mm}$ ) and a large wheel (diameter $210 \mathrm{~mm}$ and width $50 \mathrm{~mm}$ ). Entry angle and exit angles 
are found for both plain wheels. The maximum specific angle is found for three cases, i.e., at $a_{0}=0,0.15$ and 0.3 (Section 3). The normal stress and shear stress are determined for both rigid wheels which travel on TRI-1 soil simulant. The vertical force is also determined for all cases and compared with wheel weights. It is found that Wong-Reece model gives the optimum value for the large wheel, and performs better than other models, i.e., $w \cong F_{z}$ (vertical force). Finally, ranges of normal stress and shear stress are reported, i.e. DNSR (Dimensionless Normal Stress Ratio) and DSSR (Dimensionless Shear Stress Ratio) found for both wheels are graphically presented in this paper.

\section{State of the art - literature review}

Ishigami et al. (2011) carried out wheel-terrain interaction studies on flexible and rigid wheels to evaluate traction performance on rigid/deformable terrain. Since there was deformation on both rigid and soft terrain, the proposed wheel-terrain interaction model was divided into three sections - wheel front section, wheel deflected section and wheel rear section. The traction force found from calculations of normal stress and shear stress generated at each section was considered. Simulation studies were also carried out to validate the proposed model. The optimal flexible wheel gave better traction performance.

Yoshikawa et al. (2017) developed a rover model based on the reference model using Modelica language to control the wheel mechanism of the lunar exploration rover 'ATHLETE' which was developed by NASA/JPL. The rover was equipped with six limbs along with six joints to achieve high performance. The longitudinal force model for the rover control was identified. It was necessary to determine the lateral force which helped one to improve the mobility on a loose soil.

Yoshida and Hamano (2001) carried out studies on the kinematic behaviour and locomotion of a lunar rover with controlling slip and traction mechanisms of the wheels. Experiments were conducted on a single wheel test bed to notice the physical behaviour and to verify the traction model and its parameters. Also a slip based control method was proposed and tested. It was shown that minimization of the slip ratio and limiting the velocity overcame the problem of wheel getting stuck in the soil.

Ding et al. (2014) proposed an improved model for wheel-soil interaction mechanics. Normal stress and shear stress were simplified to give analytical equations for finding the drawbar pull and torque.

Ding et al. (2011) carried out experiments using a test bed to measure the wheel sinkage, drawbar pull and normal force for six different types of wheels. The conventional normal stress and shear stress distribution models were improved from the analysis of experimental results. A mathematical model was derived by integrating the distributed stresses to predict the mechanics of the rigid wheel that moved on sandy terrain. Experimental results showed an incremental slip ratio from 0.05 to 0.6 . The errors were less than $10 \%$ for the improved models of all wheels when compared with the experimental data.

Sutoh et al. (2010) conducted experiments using a mono-track rover and a 4-wheeled robot with different weights to evaluate the effect of rover weight on its mobility. Using a two-wheeled rover, experiments were carried out to examine the effect of wheel diameter and width on its mobility. Experimental results were compared with simulation. Pull and forces were found to evaluate the travelling performance, where the stress distribution findings were the basic. It was concluded that an increase in the rover weight did not change its travelling performance for the track mechanism, whereas decreased it for the wheeled mechanism. Wheel diameter rather than wheel width contributed more to the travelling performance. 
Higa et al. (2016) conducted experiments using a single wheel test bed on toyoura sand and lunar regolith simulant (FSJ-1) to measure 3-dimensional stress distribution on the wheel (rigid). Three slip conditions were considered for the measurements through experiments, i.e., $0 \%, 40 \%$ and $80 \%$. The measurements showed the same trend for both toyoura sand and lunar regolith stimulants. All errors from the experimental fell below $11 \%$.

\section{Wheel-soil interaction studies}

When a wheel moves on a soft soil, radial and tangential stresses generate beneath the surface. These stresses are used in the calculation of forces, most importantly to find the vertical force and compare it with the wheel weight $\left(F_{z} \cong w\right)$, in order to improve its performance. In the present study, three models are considered for analysis of a wheel (small and large) that travels on TRI-1 soil simulant and comparison of all model results. The stress distribution model is shown in Fig. 1. Three models which are considered in the study are given in Table 1. Detailed analysis of stress distribution models and their comparison are explained.

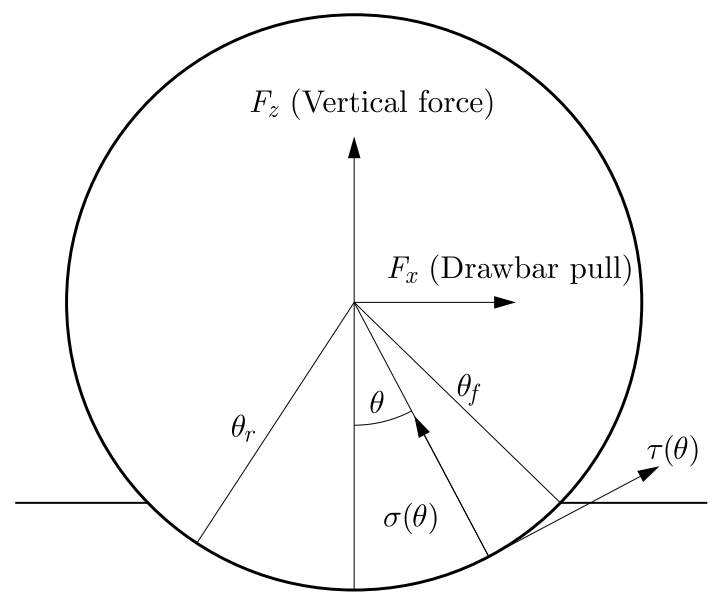

Fig. 1. Stress distribution of a plain wheel model

\subsection{Normal stress distribution models}

When a wheel travels over a loose soil, normal stress develops beneath the surface. The maximum normal stress occurs at the transition point between two the zones, forward and rearward zones, i.e., at the maximum specific angle $\theta_{m}$. Three models for the normal stress distribution are considered (Table 1).

$\theta_{f}$ - entry angle (the angle from the vertical line to the point at which the wheel initially comes in contact with the soil)

$$
\theta_{f}=\cos ^{-1}\left(1-\frac{h}{r}\right)
$$

$\theta_{r}$ - exit angle (the angle from the vertical line to where the wheel departs from the soil, and this value is generally assumed to be zero)

$$
\theta_{r} \cong 0 \quad \text { or } \quad \theta_{r}=\cos ^{-1}\left(1-\frac{k h}{r}\right)
$$

$\theta_{m}$ - maximal specific angle (the specific wheel angle where the normal stress is maximum)

$$
\theta_{m}=\left(a_{0}+a_{1} s\right) \theta_{f}
$$


where $a_{0}$ and $a_{1}$ are parameters depending on the wheel-soil interaction, and $a_{0} \cong 0.4,0 \leqslant a_{1} \leqslant$ 0.3 (assumed values, given by Wong from 1965).

$h$ - defines how much the wheel initially compacts the soil when it contacts with the soil surface.

$k h$ - defines how much the soil recovers in height following the wheel when it departs the soil surface.

$k$ - wheel sinkage ratio (which denotes the ratio between the front and rear sinkages of the wheel). The value of $k$ depends on the wheel surface-pattern, slip ratio and soil characteristics. The value of $k$ lies below 1.0 when soil compaction occurs, but can be more than 1.0 when the soil is dug by the wheel and transported to the region behind the wheel.

Table 1. Models of the normal stress distribution

\begin{tabular}{|c|c|c|c|}
\hline No. & Model & Normal stress & Remarks \\
\hline \multirow{3}{*}{1} & \multirow{3}{*}{$\begin{array}{l}\text { Reece, } 1965 \\
(\text { model } 1)\end{array}$} & $\sigma(\theta)=\sigma_{\max }\left(\cos \theta-\cos \theta_{f}\right)^{n}$ & $\theta_{m} \leqslant \theta \leqslant \theta_{f}$ \\
\hline & & $\begin{array}{c}\sigma(\theta)=\sigma_{\max } \\
\cdot\left[\cos \left\{\theta_{f}-\left(\left(\theta-\theta_{r}\right) /\left(\theta_{m}-\theta_{r}\right)\right)\left(\theta_{f}-\theta_{m}\right)\right\}-\cos \theta_{f}\right]^{n}\end{array}$ & $\theta_{r} \leqslant \theta \leqslant \theta_{m}$ \\
\hline & & $\sigma_{\max }=\left(c k_{c}+\rho k_{\phi} b\right)(r / b)^{n}$ & \\
\hline \multirow{3}{*}{2} & \multirow{3}{*}{$\begin{array}{c}\text { Bekker, } \\
1969 \\
\text { (model 2) }\end{array}$} & $\sigma(\theta)=\sigma_{\max }\left[\left(\cos \theta-\cos \theta_{f}\right) /\left(\cos \theta_{m}-\cos \theta_{f}\right)\right]^{n}$ & $\theta_{m}<\theta<\theta_{f}$ \\
\hline & & $\begin{aligned} \sigma(\theta)=\sigma_{\max } & {\left[\left(\cos \left\{\theta_{f}-\left(\left(\theta-\theta_{r}\right) /\left(\theta_{m}-\theta_{r}\right)\right)\left(\theta_{f}-\theta_{m}\right)\right\}\right.\right.} \\
& \left.\left.-\cos \theta_{f}\right) /\left(\cos \theta_{m}-\cos \theta_{f}\right)\right]^{n}\end{aligned}$ & $\theta_{r}<\theta<\theta_{m}$ \\
\hline & & $\sigma_{\max }=\left(c k_{c}+\rho k_{\phi} b\right)(r / b)^{n}\left(\cos \theta_{m}-\cos \theta_{f}\right)^{n}$ & \\
\hline \multirow[b]{2}{*}{3} & \multirow{2}{*}{$\begin{array}{c}\text { Wong and } \\
\text { Reece, } 1967 \\
(\text { model 3) }\end{array}$} & $\sigma(\theta)=\left(k_{c} / b+k_{\phi}\right) r^{n}\left(\cos \theta-\cos \theta_{f}\right)^{n}$ & $\theta_{m} \leqslant \theta \leqslant \theta_{f}$ \\
\hline & & $\begin{array}{c}\sigma(\theta)=\left(k_{c} / b+\rho k_{\phi}\right) r^{n} \\
\cdot\left[\cos \left\{\theta_{f}-\left(\left(\theta-\theta_{r}\right) /\left(\theta_{m}-\theta_{r}\right)\right)\left(\theta_{f}-\theta_{m}\right)\right\}-\cos \theta_{f}\right]^{n}\end{array}$ & $\theta_{r} \leqslant \theta \leqslant \theta_{m}$ \\
\hline
\end{tabular}

where: $n$ - sinkage exponent, $b$ - wheel width, $c$ - cohesion stress of the soil

$r$-wheel radius $\rho$ - soil bulk density, $k_{c}, k_{\phi}$ - pressure-sinkage moduli

Normal stress distribution models of the Reece (1965) and Bekker (1969) models are explained in Fig. 2.

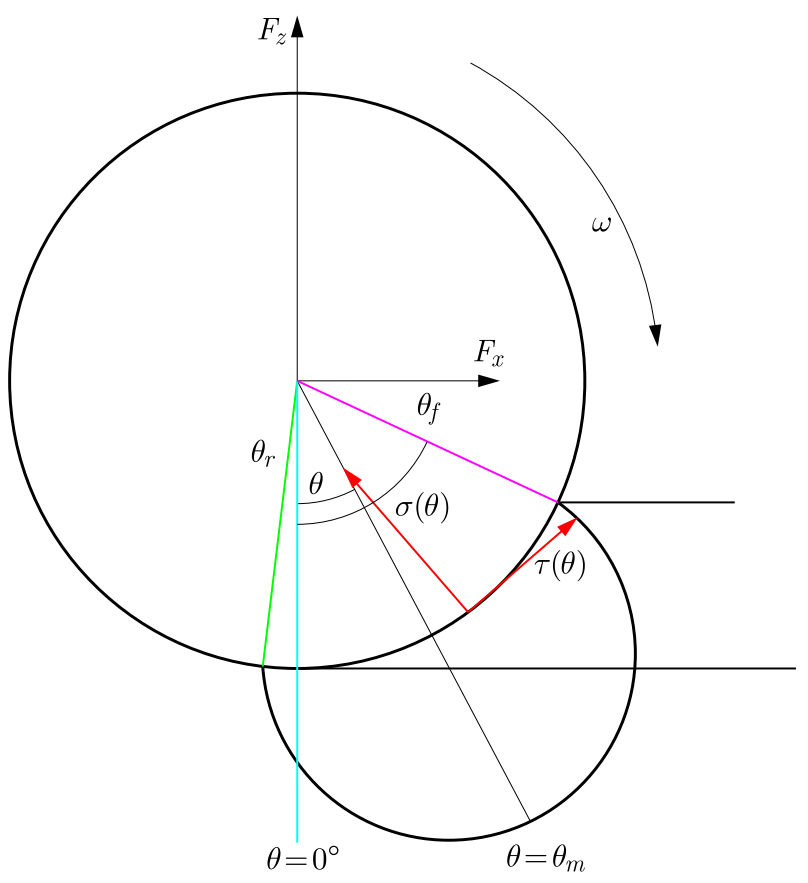

Fig. 2. Wheel soil model 


\subsection{Shear stress model for a rigid wheel}

The shear stress distribution model was given by Janosi and Hanamoto in 1961 to find the shear stress developed beneath the wheel as shown in Figs. 1 and 2. It was applicable to the Reece, Bekker and Wong-Reece models. The shear stress distribution model is tabulated in Table 2 .

Table 2. Shear stress model for the rigid wheel

\begin{tabular}{|c|c|c|}
\hline $\begin{array}{c}\text { Janosi and } \\
\text { Hanamoto }(1961)\end{array}$ & $J[\mathrm{~m}]$ & Remarks \\
\hline \multirow{2}{*}{$\tau_{x}=[c+\sigma(\theta) \tan \phi]$} & $j(\theta)=r\left[\theta_{f}-\theta-(1-s)\left(\sin \theta_{f}-\sin \theta\right)\right]$ & without lugs \\
\cline { 2 - 3 }$\cdot[1-\exp (-j(\theta) / k)]$ & $j(\theta)=r\left[\theta_{f}^{1}-\theta-(1-s)\left(\sin \theta_{f}^{1}-\sin \theta\right)\right]$ & \\
& $\theta_{f}^{1}=\cos ^{-1}((r-z) /(r+H))$ & with lugs \\
& $H-$ lug height, $z-$ wheel sinkage & \\
\hline
\end{tabular}

where: $\phi$ - internal friction angle of the soil, $j$ - soil deformation

$k$ - shear deformation modulus (depending on the shape of the wheel surface) $s$ - wheel slip (given as the ratio of wheel width to the wheel radius)

\subsection{Calculation of the vertical force of the wheel}

The weight bearing force or the vertical force is required to prevent a wheel from sinkage into the loose soil. The vertical force $F_{z}$ is obtained by integrating the vertical components of normal stress $\sigma(\theta)$ and shear stress $\tau_{x}$ from the entry angle $\theta_{f}$ to the departure angle $\theta_{r}$. Three models are considered in the present study.

The vertical force is given in Table 3.

Table 3. Models for calculation of the vertical force

\begin{tabular}{|c|c|c|c|}
\hline No. & As per & Vertical force & Conditions/remarks \\
\hline \hline 1 & Reece, 1965 & \multirow{2}{*}{$F_{z}=r b \int_{\theta_{r}}^{\theta_{f}}\left[\tau_{x} \sin \theta+\sigma(\theta) \cos \theta\right] d \theta$} & \\
\hline 2 & Bekker, 1969 & & - \\
\hline \multirow{2}{*}{3} & Wong and & $F_{z}=r b \int_{\theta_{r}}^{\theta_{f}}\left[\tau_{x} \sin \theta+\sigma(\theta) \cos \theta\right] d \theta$ & without lugs \\
\cline { 3 - 5 } & Reece, 1967 & $F_{z}=b \int_{\theta_{r}}^{\theta_{f}}\left[r_{s} \tau_{x} \sin \theta+r \sigma(\theta) \cos \theta\right] d \theta$ & with lugs \\
\hline
\end{tabular}

\subsection{Plane rigid wheels of the present study}

Small and large wheels are considered in the analysis. Using a single wheel test bed, tests are performed on flat terrain (TRI-1 soil simulant), and the average sinkage is taken from 3 trails. The travelling distance and travelling time are also noted from the test. All the values which are considered are the average from 3 trails. Wheel parameters are noted in Table 4 .

Table 4. Parameters for calculation of the vertical force

\begin{tabular}{|c|l|c|c|}
\hline No. & \multicolumn{1}{|c|}{ Parameters } & Small wheel & Large wheel \\
\hline \hline 1 & Wheel diameter $d[\mathrm{~mm}]$ & 160 & 210 \\
\hline 2 & Wheel width $b[\mathrm{~mm}]$ & 32 & 50 \\
\hline 3 & Wheel weight $w[\mathrm{~N}]$ & 52.2 & 67.4 \\
\hline 4 & Wheel sinkage $z$ or $h[\mathrm{~mm}]$ & 2.66 & 3.0 \\
\hline
\end{tabular}




\subsection{TRI-1 or Tiruchirappalli-1 soil simulant}

TRI-1 or Tiruchirappalli-1 simulant is an anorthosite based simulant developed and characterized [sugali] to resemble the properties of Apollo-16 lunar soil simulant. Geotechnical and mechanical properties of TRI-1 are found by conducting various tests like a direct shear test, plate load test, compaction test, etc. The properties of TRI-1 soil simulant are given in Table 5 .

Table 5. TRI-1 Soil simulant properties (Sreenivasulu, 2014)

\begin{tabular}{|c|l|c|}
\hline No. & \multicolumn{1}{|c|}{ Simulant properties } & Value \\
\hline \hline 1 & Cohesion $c[\mathrm{kPa}]$ & 0.36 \\
\hline 2 & Internal friction angle $\phi\left[^{\circ}\right]$ & 43.33 \\
\hline 3 & Coefficient of cohesion modulus $k_{c}\left[\mathrm{kN} / \mathrm{m}^{n+1}\right]$ & 6.60 \\
\hline 4 & Coefficient of friction modulus $k_{f}\left[\mathrm{kN} / \mathrm{m}^{n+2}\right]$ & 139.00 \\
\hline \multirow{2}{*}{5} & Min. density $\rho_{\min }[\mathrm{g} / \mathrm{cc}]$ in graphs & 1.15 or $11.2762 \mathrm{KN} / \mathrm{m}^{3}$ \\
\cline { 2 - 3 } & Max. density $\rho_{\max }[\mathrm{g} / \mathrm{cc}]$ in graphs & 1.88 or $18.4342 \mathrm{KN} / \mathrm{m}^{3}$ \\
\hline 6 & Sinkage exponent $n$ & 0.404 \\
\hline \multirow{2}{*}{7} & \begin{tabular}{l} 
Shear deformation \\
modulus $K[\mathrm{~m}]$ \\
\cline { 2 - 3 }
\end{tabular} & 0.0026 \\
\cline { 2 - 3 } & $(1.02$ to $\pm 0.76 \mathrm{~cm})$ & 0.0103 \\
\hline
\end{tabular}

The plate load test is conducted to obtain the values of sinkage exponent $n$ and shear deformation modulus $K$. The obtained value of $K$ is 1.02 to $\pm 0.76 \mathrm{~cm}$. Hence, the value of $K$ ranges from $0.26 \mathrm{~cm}$ to $1.8 \mathrm{~cm}$. Therefore, the considered shear deformation values are $0.26 \mathrm{~cm}$, which is the minimum, and $1.8 \mathrm{~cm}$, which is the maximum. The last value as an average of the minimum and maximum values is $1.03 \mathrm{~cm}$. The values which are considered in the models are clearly given in Table 5.

3.6. Determination of the entry angle, exit angle and maximum specific angle

Table 6. Entry angle, exit angle and the maximum specific angle

\begin{tabular}{|c|c|c|c|c|}
\hline No. & Models & Entry angle & Exit angle & Maximum specific angle \\
\hline \multicolumn{5}{|c|}{ Small wheel $(160 \mathrm{~mm} \times 32 \mathrm{~mm})$} \\
\hline \multirow{3}{*}{1} & Reece, 1965 & \multirow{3}{*}{$14.82^{\circ}$} & \multirow{3}{*}{$10.46^{\circ}$} & $5.93^{\circ}$ \\
\hline & Bekker, 1969 & & & $6.82^{\circ}$ \\
\hline & Wong-Reece, 1967 & & & $7.71^{\circ}$ \\
\hline \multicolumn{5}{|c|}{ Large wheel $(210 \mathrm{~mm} \times 50 \mathrm{~mm})$} \\
\hline \multirow{3}{*}{2} & Reece, 1965 & \multirow{3}{*}{$13.73^{\circ}$} & \multirow{3}{*}{$9.7^{\circ}$} & $5.49^{\circ}$ \\
\hline & Bekker, 1969 & & & $6.52^{\circ}$ \\
\hline & Wong-Reece, 1967 & & & $7.55^{\circ}$ \\
\hline
\end{tabular}

\subsection{Comparison of all models for the normal stress, shear stress and vertical force}

Normal stresses, shear stresses and vertical forces are found using the stress distribution models (Tables 1 and 2) and the vertical force model (Table 3) for both plain rigid wheels considered. For three cases, i.e., at $\theta_{m}=5.93^{\circ}, 6.82^{\circ}$ and $7.71^{\circ}$, the normal stress, shear stress and vertical force are evaluated for the small wheel $(160 \mathrm{~mm} \times 32 \mathrm{~mm})$. The maximum stresses (normal and shear) occur at maximum specific angles for the minimum shear deformation modulus, i.e., $k_{1}=0.0026 \mathrm{~cm}$ (dense soil-maximum density). Similarly, for the large wheel $(210 \mathrm{~mm} \times 50 \mathrm{~mm})$, at $\theta_{m}=5.49^{\circ}, 6.52^{\circ}$ and $7.55^{\circ}$, the stresses are found to be maximum for the minimum shear 
(a)

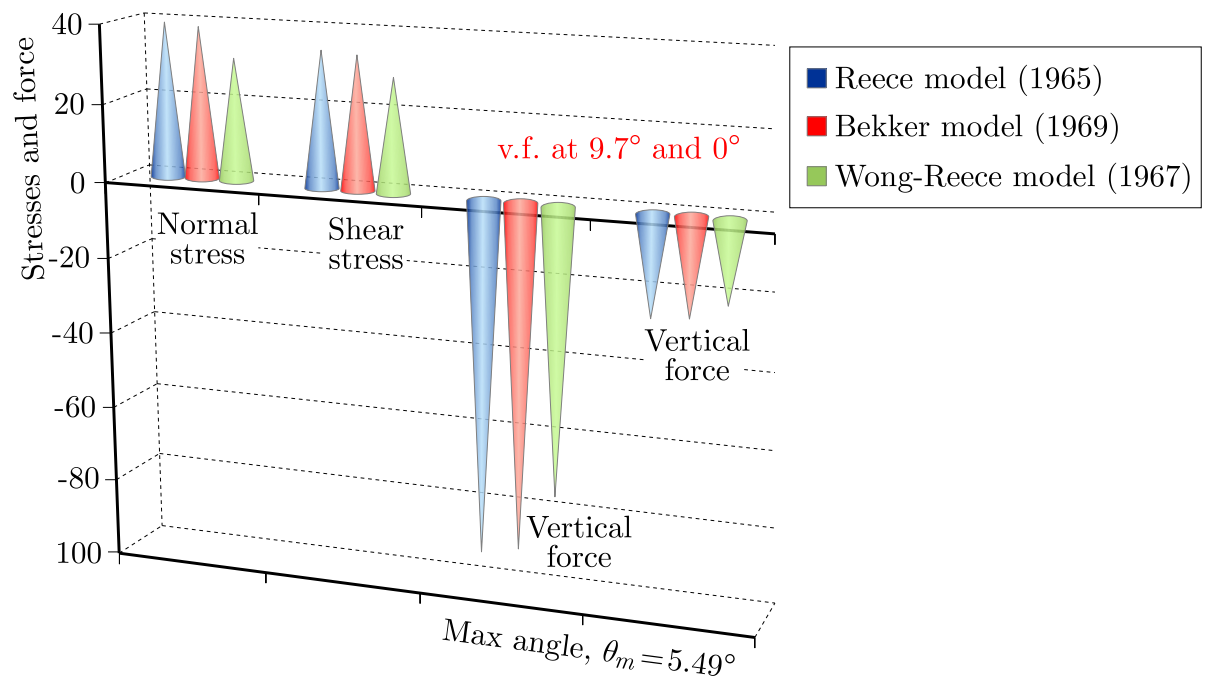

(b)

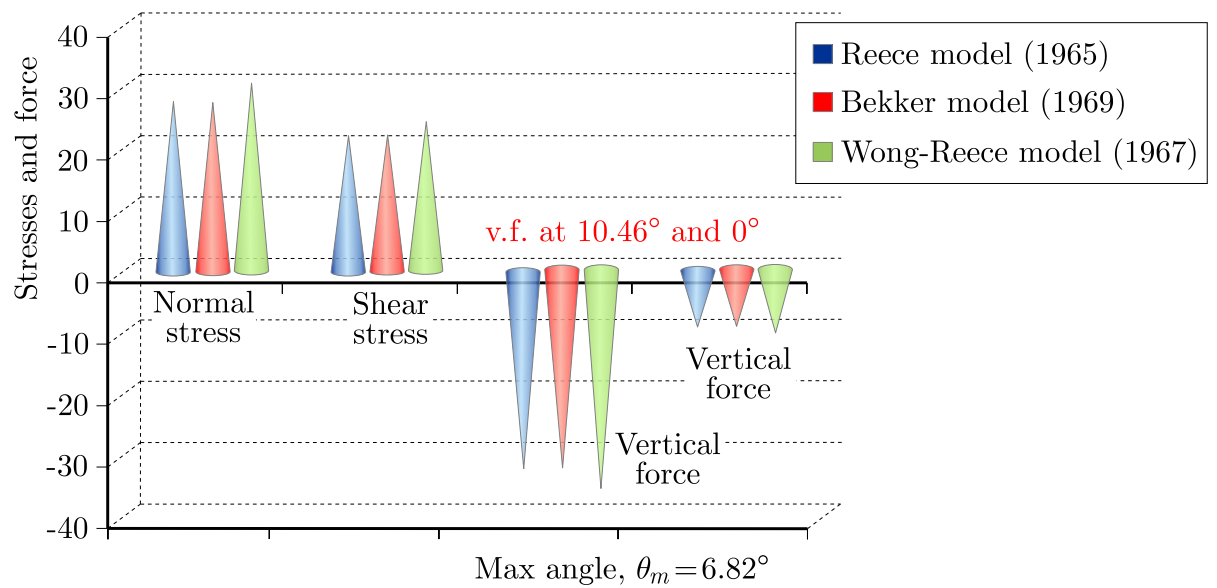

(c)

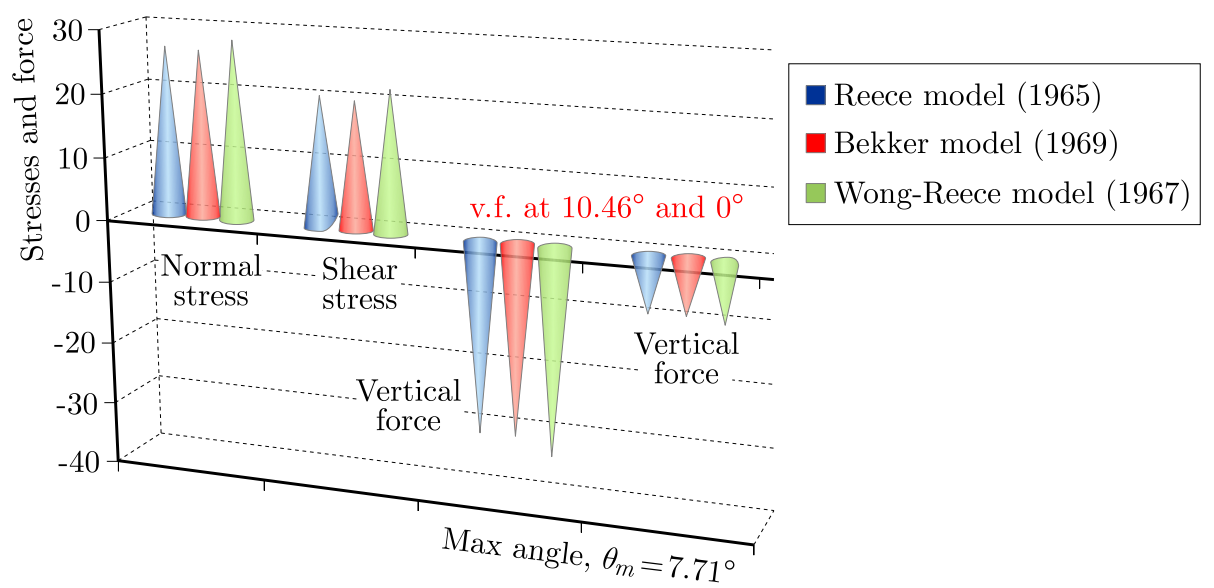

Fig. 3. Small wheel stresses, vertical force at: (a) $\theta_{m}=5.93^{\circ}$ for $k_{1}$, (b) $\theta_{m}=6.82^{\circ}$ for $k_{1}$, (c) $\theta_{m}=7.71^{\circ}$ for $k_{1}$

deformation modulus, i.e., $k_{1}=0.0026 \mathrm{~cm}$ (dense soil-maximum density). They are graphically presented in this paper.

For the small wheel (Fig. 3), the maximum normal stress is found to be $32.122 \mathrm{kN} / \mathrm{m}^{2}$ at $\theta_{m}=5.93^{\circ}$ for $k_{1}=0.0026 \mathrm{~cm}$ (Wong-Reece model). The maximum shear stress is $26.339 \mathrm{kN} / \mathrm{m}^{2}$, whereas, the minimum normal stress $26.856 \mathrm{kN} / \mathrm{m}^{2}$ at $\theta_{m}=7.71^{\circ}$ for $k_{1}=0.0026 \mathrm{~cm}$ (Bekker model) and the minimum shear stress of $20.016 \mathrm{kN} / \mathrm{m}^{2}$. 
(a)

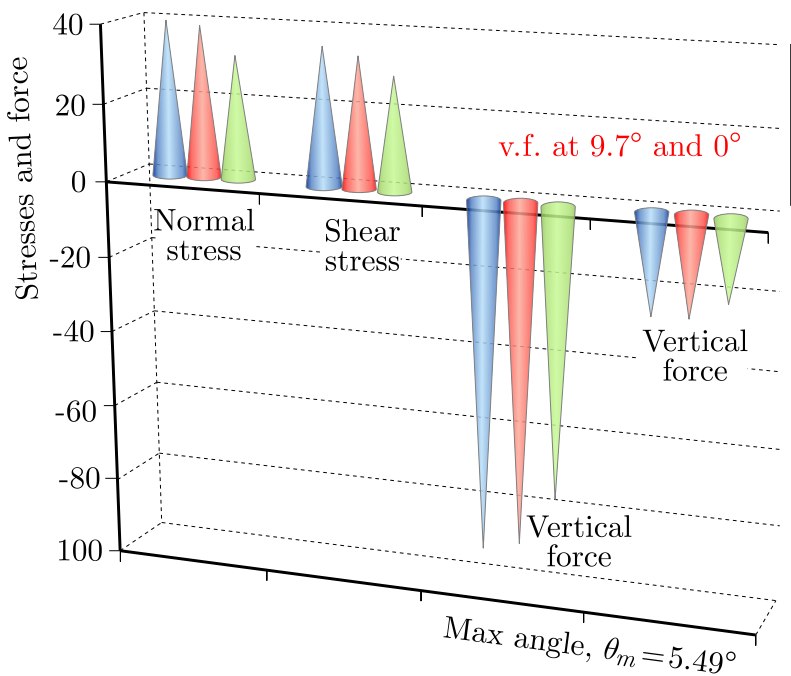

(b)

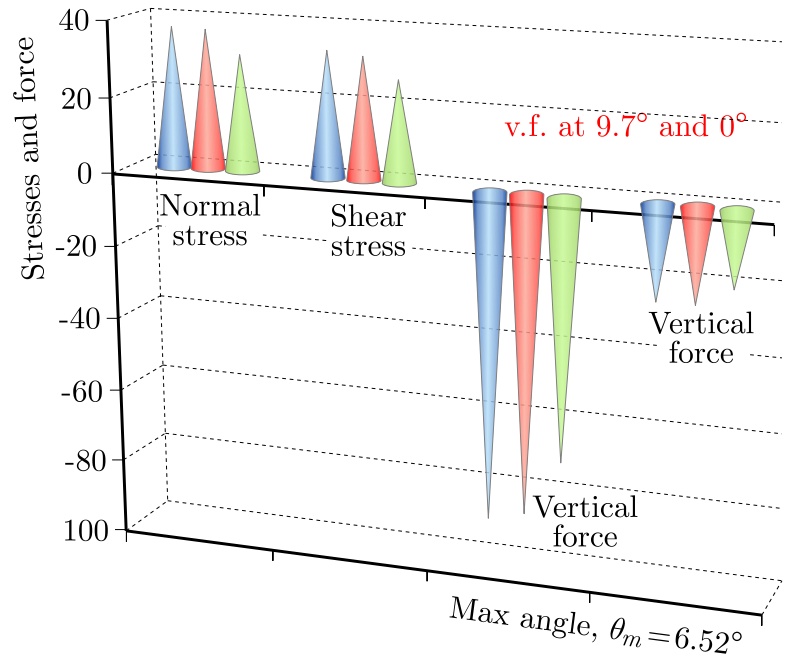

Reece model (1965)

- Bekker model (1969)

$\square$ Wong-Reece model (1967)

(c)

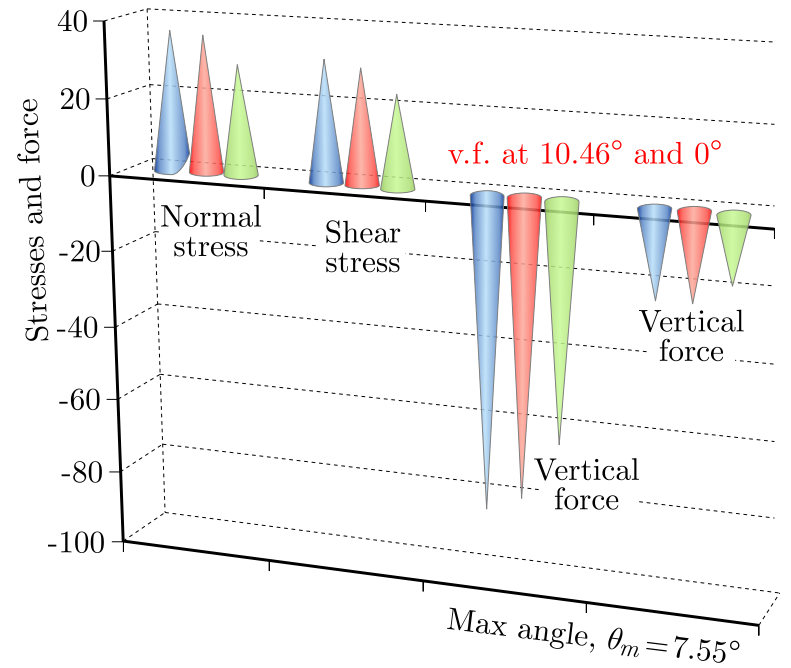

- Reece model (1965)

- Bekker model (1969)

$\square$ Wong-Reece model (1967)

- Reece model (1965)

- Bekker model (1969)

$\square$ Wong-Reece model (1967)

Fig. 4. Large wheel stresses, vertical force at: (a) $\theta_{m}=5.49^{\circ}$ for $k_{1}$, (b) $\theta_{m}=6.52^{\circ}$ for $k_{1}$, (c) $\theta_{m}=7.55^{\circ}$ for $k_{1}$ 
The vertical force is calculated for two cases of a small wheel. One is when the exit angle is zero (assumed), and the found maximum vertical force is $37.780 \mathrm{~N}$ (Wong-Reece model), and the other case, when the exit angle is $10.46^{\circ}$ (calculated from equation (3.2)). Here, the vertical force is less than the wheel weight, i.e., $F_{z}(37.780 \mathrm{~N})<w(52.189 \mathrm{~N})$. There is a possibility of more sinkage and more deflection when it travels on a loose soil, as the resisting force is less than the weight of the wheel. This can be improved by adding lugs or optimizing the wheel.

Figures $4 \mathrm{a}$ to $4 \mathrm{c}$ indicate analytical results for the large wheel.

For the large wheel, the maximum normal stress is found to be $39.016 \mathrm{kN} / \mathrm{m}^{2}$ at $\theta_{m}=5.49^{\circ}$ for $k_{1}=0.0026 \mathrm{~cm}$ (Reece model) and the maximum shear stress of $34.930 \mathrm{kN} / \mathrm{m}^{2}$. At the same time, the minimum normal stress is $28.002 \mathrm{kN} / \mathrm{m}^{2}$ at $\theta_{m}=7.55^{\circ}$ for $k_{1}=0.0026 \mathrm{~cm}$ (Wong-Reece model) and the minimum shear stress $23.540 \mathrm{kN} / \mathrm{m}^{2}$.

The vertical force is calculated for two cases of large wheel. One is when the exit angle is zero (assumed), with the maximum vertical force of $70.088 \mathrm{~N}$ (Wong-Reece model) and the other case, when the exit angle is $9.7^{\circ}$ (calculated from equation (3.2)). Here, the vertical force is greater than the wheel weight, i.e., $F_{z}(70.088 \mathrm{~N}) \geqslant w(67.444 \mathrm{~N})$. There is a possibility of no sinkage and no deflection when the wheel travels on a loose soil, as the resisting force is more than the weight of the wheel. This can be considered in the future wheel soil interaction studies or optimization of the wheel for different conditions and better results.

\subsection{Dimensionless Normal Stress Ratio (DNSR) and Dimensionless Shear Stress Ratio (DSSR)}

The dimensionless stress ratio for the small and large wheels have been found and graphically shown in Figs. 5 and 6.

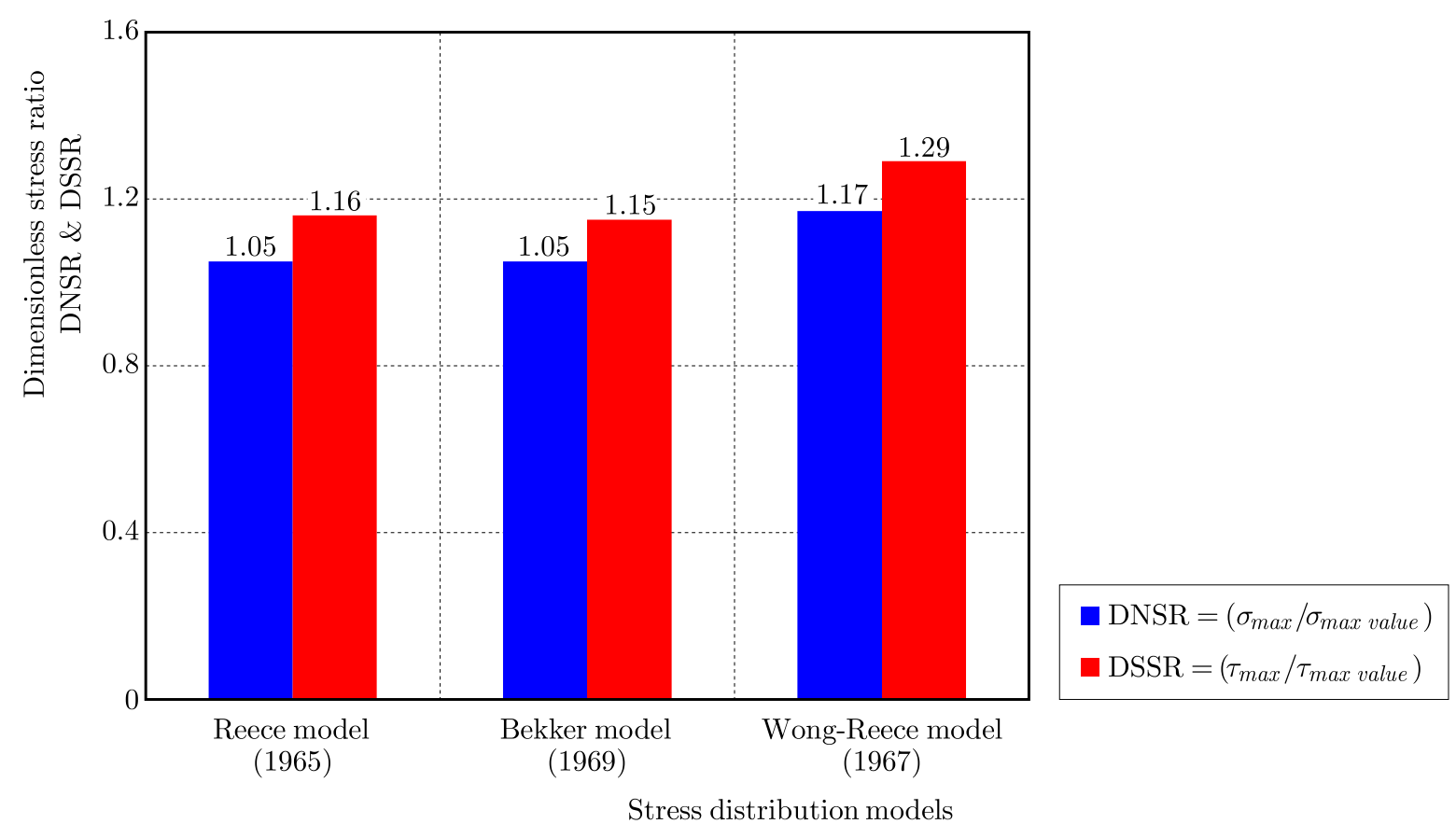

Fig. 5. Dimensionless stress ratio for the small wheel

The dimensionless normal stress ratio and dimensionless shear stress ratio are maximum for the Wong-Reece model comparing all other models for the small wheel. The Wong-Reece model is suitable for small wheels (Fig. 5), whereas, for the large wheel, the Reece model gives the maximum (Fig. 6) dimensionless stress ratio (DNSR and DSSR). 


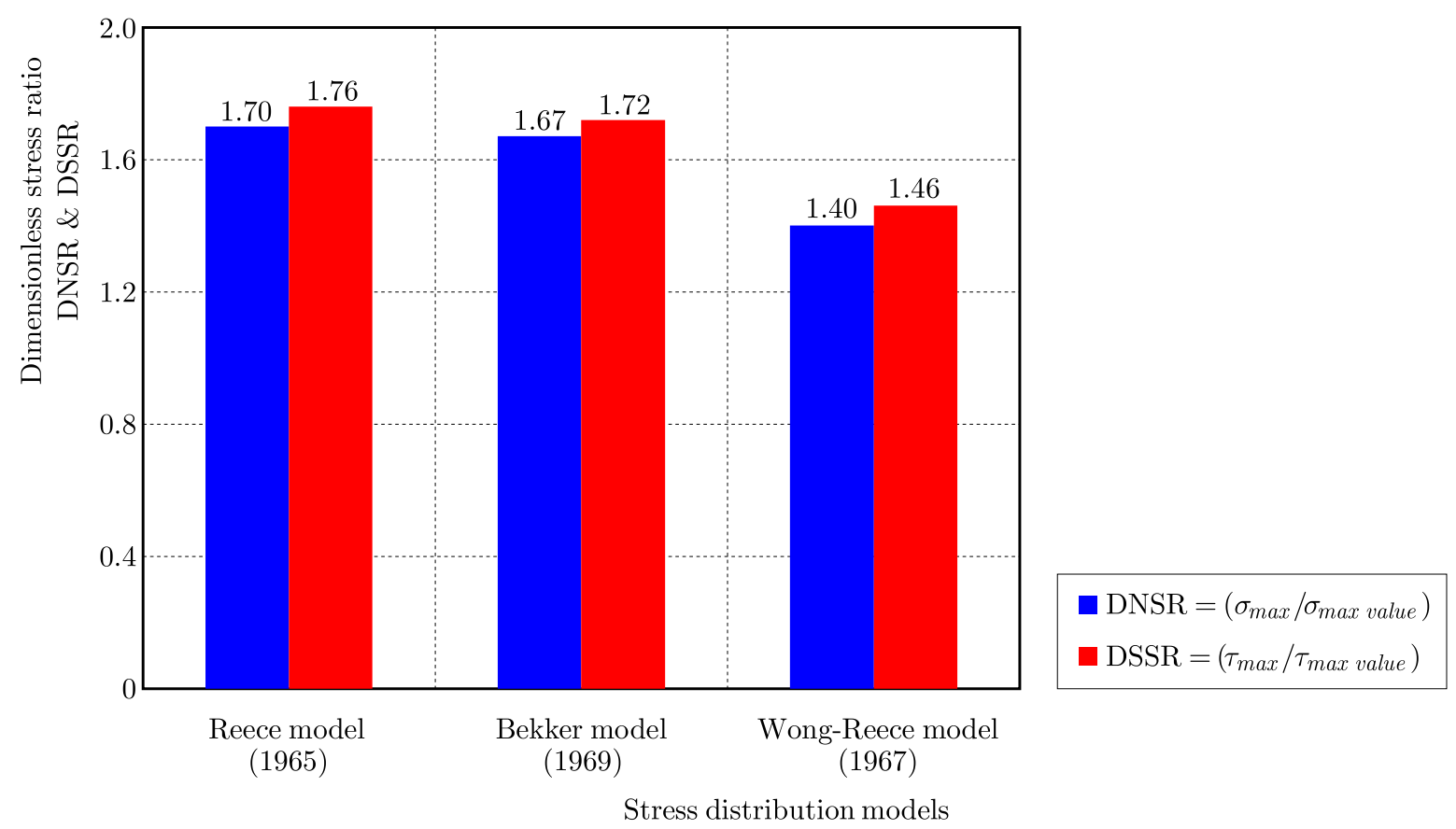

Fig. 6. Dimensionless stress ratio for the large wheel

The dimensionless stress ratios are calculated as follows:

- Dimensionless Normal Stress Ratio, DNSR $=\left(\sigma_{\max } / \sigma_{\max }\right.$ value $)$

- Dimensionless Shear Stress Ratio, DSSR $=\left(\tau_{\max } / \tau_{\max }\right.$ value $)$

\section{Results and discussions}

- From Figs. 3 and 4, it is found that the normal stress, shear stress and vertical force decrease with a rise in the maximum specific angle $\theta_{m}$.

- The maximum normal stress also decreases with the rise in the maximum specific wheel angle $\theta_{m}$. the maximum normal stress results in the maximum shear stress distribution and the maximum vertical force (Figs. 3 and 4 ).

- From Figs. 3 and 4 , it is found that the maximum shear stress at $k_{1}$ is greater than the extreme shear stress at $k_{3}$, as shown graphically. It is also noted that the maximum normal shear stresses are obtained at the minimum specific angle for the maximum density rather than for an increase in $\theta_{m}$.

- From Fig. 3a, it is found that the normal stress obtained is maximum (Wong-Reece model) than in other models.

- In the case of the large wheel $(210 \mathrm{~mm} \times 50 \mathrm{~mm})$, Figs. $4 \mathrm{a}$ to $4 \mathrm{c}$, it is found that the normal stress decreases with a rise in the maximum specific angle $\theta_{m}$, the minimum density induces the minimum normal stress whereas the maximum density causes the maximum normal stress.

- The shear stress is maximum at $\theta_{m}=5.93^{\circ}$ for a dense soil when $k=k_{1}$.

- Comparing with the small wheel, the obtained normal stress and shear stress is maximum (Reece) for the large wheel on TRI-1 soil simulant.

- From Fig. 4a, it is found that similar phenomena of the maximum normal stress at $\theta_{m}=5.49^{\circ}$ for the dense soil are obtained. Also for $k_{1}$, the shear stress is maximum in the same case. In all other cases, the shear stress decreases with an increase in $\theta_{m}$. The found maximum vertical force is $70.088 \mathrm{~N}$ (Wong-Reece model). 
- The maximum vertical force is $70.088 \mathrm{~N}$ (Wong-Reece model) for the large wheel. Here, the vertical force is greater than the wheel weight, i.e., $F_{z}(70.088 \mathrm{~N}) \geqslant w(67.444 \mathrm{~N})$, and there is a possibility of no sinkage and no deflection when the wheel travels on a loose soil, as the resisting force is greater more than the weight of the wheel. In all other cases of the small and large wheels, the vertical force cannot resist its wheel weight because of either very low resisting value or being more resistant (rolling without friction).

- In Fig. 5, one can see that the small wheel gives the maximum dimensionless stress ratio for the Wong-Reece model (DNSR $=1.17$ and DSSR $=1.29$ ).

- From Fig. 6, it is found that the large wheel gives the maximum dimensionless stress ratio for the Reece model (DNSR $=1.7$ and DSSR $=1.76$ ).

\section{Conclusion}

Analytical studies on a small wheel $(160 \mathrm{~mm} \times 32 \mathrm{~mm})$ and a large wheel $(210 \mathrm{~mm} \times 50 \mathrm{~mm})$ have been carried out using three models to determine normal and shear stress distributions beneath the wheel when it interacts with the soil, and also vertical forces have been evaluatedin the same conditions. Dimensionless Normal Stress Ratio (DNSR) and Dimensionless Shear Stress Ratio are introduced. Comparing the results of both wheels for all models, it is concluded that the Wong-Reece model gives the maximum normal stress and shear stress. Future scope of investigation aims at introducing lugs to the existing solutions and comparing both plain and lugged wheels. The work is currently progressing in this direction.

\section{Acknowledgment}

The technical support received from National Institute of Technology Tiruchirappalli, for the research work is gratefully acknowledged. We also acknowledge with grateful thanks to the Ministry of Human Resource Development (MHRD), India, for the Ph.D. Scholarship received to carry out the research work.

\section{References}

1. Ding L., Deng Z., Gao H., Tao J., Iagnemma K.D., Liu G., 2014, Interaction mechanics model for rigid driving wheels of planetary rovers moving on sandy terrain considering multiple effects, Journal of Field Robotics, 32, 6, 827-859

2. Ding L., Gao H., Deng Z., Nagatani K., Yoshida K., 2011, Experimental study and analysis on driving wheels' performance for planetary exploration rovers moving indeformable SOI l, Journal of Terramechanics, 48, 27-45

3. Ding L., Gao H., Deng Z., Yoshida K., Nagatani K., 2009, Slip ratio for lugged wheel of planetary rover in deformable soil: definition and estimation, Intelligent Robots and System, IROS 2009, IEEE/RSJ International Conference

4. Higa S., Sawada K., Teruya K., Nagaoka K., Yoshida K., 2016, Three dimensional stress distribution of a rigid wheel on lunar regolith simulant, Proceedings of the 13th International Symposium on Artificial Intelligence, Robotics and Automation in Space, \#S-9a-3

5. Iagnemma K., Kang S., Shibly H., Dubowsky S., 2004, Online terrain parameter estimation for wheeled mobile robots with application to planetary rovers, IEEE Transactions on Robotics, 20,5

6. Ishigami G., Otsuki M., Kubota T., Iagnemma K., 2011, Modeling of flexible and rigid wheels for exploration rover on rough terrain, Proceedings of the 28th International Symposium on Space Technology and Science, Okinawa, Japan 
7. Lizuka K., Kubota T., Kubota T., 2010, Measurement of stress distribution of flexible wheels for lunar rover, Robotics (ISR), 41st International Symposium on Robotics (ROBOTIK), Munich, Germany

8. SReenivasulu S., 2014, Development and Characterisation of TRI-1: An engineered lunar soil simulant and studies on wheel soil interaction, Ph.D. Thesis, Department of Civil Engineering, National Institute of Technology, Tiruchirappalli

9. Sutoh M., Yusa J., Nagatani K., Yoshida K., 2010, Travelling performance evaluation of planetary rovers on weak soil, Journal of Field Robotics, January, 546-551

10. Yoshida K., Hamano H., 2001, Motion Dynamics and Control of a Planetary Rover with Slip-Based Traction Model Robotics, Laboratory in Tsukuba Space Center, NASDA, Japan

11. Yoshikawa H., Oda T., Nonaka K., Sekiguchi K., 2017, Modeling and simulation of wheel driving systems based on terramechanics for planetary exploration rover using modelica, Proceedings of the 12th International Modelica Conference, Prague, Czech Republic, 901-907

Manuscript received September 22, 2017; accepted for print May 10, 2019 